\title{
Radio Diffusion: Re-Collecting International Broadcasting in the Archive of Radio Netherlands WorldWide
}

\author{
Alexander Badenoch
}

In 2012, a vital era in international broadcasting came to an end. Radio Nederland Wereldomroep (also known as Radio Netherlands Worldwide, hereafter $\mathrm{RNW}$ ), an organization that had long been in the forefront of shortwave broadcasting, had its budget slashed, effectively ending most of its operations and services (RNW 2012; Dohmen 2012), leaving only a small organization aimed at countries where press freedom is threatened. Besides closing down most future production, this also meant RNW's operations to maintain and re-use its own past would end. As a statement from the station's direction put it specifically in reference to the archive of the station's website: "Archives cost money. RNW unfortunately can't permit itself to keep its full archive together on its current, lower budget." (Quoted in: Schaap 2015) ${ }^{1}$ This archive of journalism on the website was just one of many archived materials of RNW, both digitized and physical, that would have to find either a new home or oblivion.

Following a period of uncertainty surrounding the fate of many materials, agreements have now been made between the Dutch national audiovisual archive, the Netherlands Institute for Sound and Vison (Nederlands Institut voor Beeld en Geluid, hereafter NISV ${ }^{2}$ ) and the National Archives of the Netherlands (Nationaal Archief, hereafter NA) to preserve the bulk of the sound, photographic and written records. (Lauwers 2017a) The process of transfer, selection, (digital) preservation and cataloging implied in this decision remains to be done as of this writing, but observing the process up to now provides a key glimpse into the ways in which such processes can shape the stories of radio. In particular, the collections' movement from a working broadcasting institution (mostly) into dedicated public, national archives allows us an impor-

1) This and all other quotes from Dutch sources translated by the author.

$\mathbf{2} \mid$ While most acronyms in this chapter are based on their original Dutch title, NISV uses both its English title and acronym in international settings, so I have used that here. 
tant glimpse into a process of archivalization. This term was coined by archival scientist Eric Ketelaar to refer to the "conscious or unconscious choice (determined by social and cultural factors) to consider something worth archiving." (Ketelaar 2001: 133) In the case at hand, archivalization appears in a process of re-contexualization of records that were already preserved once and about which new choices, based in part on new social and cultural factors, are being made (ibid.: 137). Crucially, this notion demands a reflexive view of archival records: archivalization speaks not only about the records selected, but about the nature and values of the archives themselves. With this in mind, there arise as well the more radio-specific questions raised by Shawn VanCour in relation to the US Radio Preservation Task Force: what is the nature of the radio archive in the present age, and what is it good for? (VanCour 2016: 396)

Understanding this particular process of archivalization is doubly vital given the peculiar - and usually peripheral - place international broadcasting generally, and RNW specifically, has tended to occupy within national consciousness and history. As the 'voice of the nation,' either addressing foreign populations or national diasporas - and usually both - the national significance of international broadcasters has been long-established at both national and international level (Codding 1959; Spohrer 2013). Explicitly aimed beyond the boundaries of the nation, however, often in languages unintelligible to much of the 'home' population, their activities do not always fit neatly within the canons of national identity or history. Unlike domestic national broadcasters, whose mission of serving national publics has been somewhat consistent, international broadcasters have had divergent, evolving and overlapping purposes (Browne 1982). These can include serving national diasporas (Robertson 2008), strengthening colonial and post-colonial ties (Potter 2012), psychological warfare and propaganda in times of conflict (Wood 1994: 2-4; Nelson 2003; Briggs 1970), promoting national trade, and supporting global development ${ }^{3}$ All of these have played some role in RNW's development. Making those missions known to domestic audiences has often been a separate operation, very often relying far more on visual media (Komska 2015; Badenoch and Hagedoorn 2018: 12-15), which in the case of the RNW involved maps, newsreels, and the image of its purpose-built airplane-shaped building in Hilversum. In its early years, RNW met with strong skepticism for broadcasting in foreign languages - particularly non-Western ones (Haslach 1983, 89) - only to see these services later become far more the core of RNW's mission (ibid.: 98-99). For that matter, the budget cuts that led to RNW's closing reflect a similar marginal status in public consciousness, and statements from the xenophobic party supporting the governing coalition at the time further highlight enduring suspicions of its

$3 \mid$ n the difficulty in defining international broadcasting, see David Fernandez Quijada in this volume. 
mission. (Dohmen 2012) As Gillespie and Webb show, international broadcasting's obvious international stories of a nation maintaining various forms of contacts beyond its borders are built upon a number of transnational stories, not least of various diasporic actors whose work and hybrid voices make up the program output and their interactions within the broadcasting institution. (Gillespie and Webb 2013)

Heritage collections in the digital age are largely approached in terms of what might be called 're-collection:' that is, how archival material can be linked, networked or aggregated potentially to tell new stories (see Sonja de Leeuw's chapter in this volume). Large aggregator portals such as EUscreen and Europeana have moved from being merely central repositories focused on access to attempting to provide themed portals around specific content, themes or events usually in a transnational perspective, such as Europeana's First World War (https://www.europeana.eu/portal/en/collections/world-war-I), or migration collections https://www.europeana.eu/portal/en/collections/migration. A significant amount of the work of collecting and preserving in the digital era thus involves making digital heritage assets findable and linkable. At the same time, such activities are based around conditions of 'diffusion': distribution of heritage objects across separate institutions and collections the boundaries of which (digital) networking promises fruitfully to obviate or explode - at least in theory. Surveying the US archival landscape, VanCour notes this dynamic at work, stating that

[w] hile working to reaggregate programming materials that networks dispersed throughout space and time, broadcasting archives have remained themselves divided in their locations, constituencies, and institutional mandates. (VanCour 2016: 397)

As I will show in the case of the Netherlands, a smaller country with somewhat more centralized broadcasters and archival institutions than the US, diffusion can nevertheless occur at several levels and at several moments, particularly at the moment when archival material moves from one institution to another. Decisions about preservation and location of archival materials can quickly raise the tension between what the professor of archival studies Charles Jeurgens calls thinking in terms of a collection; that is, what stories the totality can tell, and thinking in terms of the individual 'documents,' which evaluates different types of document separately and tries to place each accordingly. (personal communication, 15 Feb 2018)

This chapter examines these dynamics of diffusion and re-collection as they play out in the archivalization of RNW's materials to show how these give shape to the stories that may be told using them. It takes a roughly ethnographic approach, drawing on internal documentation produced around the process, 
as well as communication with key people involved in the preservation process, and my own experience with some of the archives in question.

Ultimately, it shows how two sets of factors intertwine to give shape to what will be RNW's archival legacy. The first set concerns the practicalities of archiving: the physical nature of the material, available space and facilities for its storage, how it is currently catalogued and how it would need to be converted, adapted or translated. The second set of factors regard the values and priorities driving preservation: what is deemed worthy of preservation, but also where and 'as what' it is preserved. After a brief overview of RNW's history and missions, I will look at the archival landscape, and in particular the collecting remits of the national archives involved to explore their priorities in collection, and how these shape their view of RNW's material. Finally, I examine how RNW materials and archival practices intersect with the archival landscape, and how this shapes the selection, location and interpretation of the material.

\section{The Diffuse Missions of Radio Netherlands}

As an institution, RNW was formally founded 15 April, 1947 during the postwar reconstruction of the Netherlands, but its roots lie in two predecessor broadcasters that strongly shaped both its mission and its international profile. First, the station built on the pioneering shortwave station developed by the Philips corporation in 1927, specifically aimed at the Dutch colonies in the East and West Indies: the Philips Omroep Hollands-Indië (Philips Broadcasting Dutch Indies, PHOHI). During the war, the shortwave broadcaster had been taken over by the Nazi forces along with all other broadcasting. At the same time, the Dutch government in exile in Great Britain soon gained airtime on the BBC with its official voice Radio Oranje, aimed back at the occupied country. (Sinke 2009; Haslach 1983: 48-58) Radio Oranje is the second important predecessor of RNW: many of its members, including its first director, were key players in Radio Herrijzend Nederland (Radio Netherlands Resurrecting) - the broadcaster under Dutch military control in the newly liberated country. Rather than becoming the domestic civilian broadcaster, this organization instead became the international broadcaster RNW. (Haslach 1983: 61ff) RNW was a foundation that was granted exclusive rights to broadcast on shortwave from the Netherlands, and also received much of its budget from the Dutch Ministry of Foreign Affairs.

After Radio Netherlands was re-established, a set of program services was established that reflected much of the former and still ongoing colonial presence of the Netherlands: Dutch, English, Afrikaans, Spanish, Indonesian, and Arabic - Portuguese was later added as well as French, initially for cultural elites in Soviet-bloc Europe, and returning later aimed at Francophone Africa. 
The Dutch-language service was aimed largely at expatriates from the metropole - as well as projecting Dutch presence in the (former) colonies. Indeed, one of the station's very first tasks included entertaining the Dutch colonial troops during the war for Indonesian independence 1945-1949. The aim of the other language services was "to 'project' the Netherlands, and to be the calling card of our nation." (RNW 1960: 22)

Each language service had its own editorial and announcing staff, alongside a general editorial staff. Beyond its direct broadcasts, two other activities were key to the organization. For one, RNW also had a very active transcription service: broadcasts produced to be included in the programming of other stations. These were produced by the same departments that made the regular broadcasts. Particularly in more recent years, programs produced and distributed locally in partnership with RNW also formed a core part of the station's mission. Beyond these efforts, the station, together with the Dutch Ministry of Foreign Affairs, also founded a (still-running) training center for foreign journalists in the 1968 (see https://rntc.com/), which served international development as well as diplomatic goals, creating lasting relationships with the Netherlands. Such an overview barely scratches the surface of RNW's activities over the course of 65 years and more, but gives an indication of the breadth of material that it might have collected.

\section{The Archival Landscape}

For those working to preserve the archive, it seemed clear that RNW's archives were of national significance and as such belonged in a national archive, although it was not immediately clear which material should go to the national audiovisual archive NISV, and which should go to the National Archives. To an extent, this is a question of the classification of RNW as national institution, funded directly by the national authority or as an (international) broadcaster, primarily concerned with media production.

Before the question of locations was posed, however, the more basic question of what items would be preserved at all was the order of the day. To guide the process of preservation, selection and re-location, a so-called 'committee of sages' with expertise from the various archives as well as broadcasting history was assembled to make a selection. (Lauwers 2017a) The focus of the committee's attention was the written - in this case paper - records of the management and of the company archives (the "directiearchief" and the "bedrijfsarchief," respectively). The former includes board meetings, internal directives and external relations of the station with entities such as the Dutch government, as well as other national and external broadcasters (the records' classification of stations from the Netherlands Antilles as 'external' though they were formally 
part of the Kingdom of the Netherlands is interesting in its own right). The company archives consist roughly of all other documents relating to the operations of RNW and includes manuscript material, listener research, correspondence, photos and a number of other items.

In its collection remit, NISV also lays out a basic division of labor. For material 'outside the audiovisual domain' it maintains a partnership with two other major national heritage institutions, the Royal Library (Koninklijke Bibliotheek or KB) and the NA, where the latter is considered "storage place for the archives of (national) authorities." (Lauwers 2013: 11) For its part, NISV's general collection policy defines its remit as "collect[ing] primarily Dutch national audiovisual heritage." This means audiovisual works produced by Dutch people in the Netherlands or abroad, or recorded or made in the Netherlands. (Lauwers 2013: 21) While it states that it aims at "including different cultures, regions, and periods" that capture "the diversity of Dutch society," (ibid.) it does not explicitly state a language policy, which turned out to be a key issue.

The arrival of the RNW collection came during a shift in NISV's collection policy on written archive material. Their 2013 collection policy makes a clear distinction between the 'core collection' of audiovisual material and the 'context collections' of equipment, photographs, scripts, and other written records which "support and deepen our understanding of the content and production of the audiovisual collections." (Lauwers 2013: 59) A recent fusion with the press museum, a re-orientation toward 'media' more generally, and the recent acquisition of a number of written archives, led to new policy that looks at written records as having independent value. The procedure for acquiring company archives of media archives were in many ways adapted directly - and literally - from the policies surrounding RNW. (Lauwers 2017b)

Unlike NISV, paper archives are central to the holdings of the National Archives, and they possess both storage space and expertise in preserving and digitizing such records. Their remit includes "the national government and social organizations and individual persons who are (or were) of national importance." (www.nationaalarchief.nl/over-het-na/ons-verhaal/missie-en-meerjarenvisie). Jeurgens notes that particularly in the digital age, it matters less whether material is placed in different institutions than that there is a single catalogue or inventory that will allow a user to find the documents, and approach them as part of a collection rather than as individual documents. (personal communication 15 February 2018) While it is not explicitly named within the documents surrounding RNW collections, the NA participates in a number of national and international networks that could potentially add meaning to the RNW collections, including the national Netwerk Oorlogsbronnen (War Sources Network, www.oorlogsbronnen.nl) that combines material about the Second World War including much on RNW's precessor Radio Oranje, as well as Gedeeld Cultureel Erfgoed ("Shared Cultural Heritage"), an international 
program devoted to Dutch trade and colonial history, in which RNW material could potentially be of interest (https://www.nationaalarchief.nl/over-het-na/ gedeeld-cultureel-erfgoed).

\section{From Institution to Archive: the Diffusive ENCOUNTER}

When examining the power of archival practice, the underlying narratives of selection are very often considered implicit and unspoken - and indeed tacitness is part of their power. (Ketelaar 2001) In the case of the RNW archive, these were made an explicit part of the process by posing the question of what needs to be reconstructed from the material. Specifically, from the point of view of the NA, this meant in the first order consideration of RNW's ins and outs as an organization - this includes the bulk of the management archive minutes of board meetings, correspondence, and annual reports. (Lauwers 2017a: 3) Based on the recommendation of RNW's archivist, documents relating to the RNTC have also been marked for inclusion. (Lauwers 2017a: 2) Consideration of program materials, particularly logbooks and program listings, were also considered part of this essential, uncontroversial core of the archive. While recommending preservation around specific themes, these have not yet been chosen.

While understanding the institution was posited as a core criterion for deciding on what records to preserve, institutional practices have strong implications for what there is to be preserved in the first place (see Birdsall in this volume) - and for the way that their collections take shape in public archives. Nearly all broadcasting collections are somewhat prone to diffusion due to the nature of broadcasting work. Preservation practices often grow somewhat organically out of a range of practical considerations not directly related to the needs or interests of academic research, but rather to an institution's demands on its own past.

Formal written documents such as board meetings and annual reports, for example, are usually produced and kept within organizations, not least for legal reasons. With regard to radio programming, preservation of written records depends on various institutional cultures which can lead to calamitous - or serendipitous - conditions for historical researchers. A mountain of paper gold for researchers was kept at RNW in the form of logbooks for transmission. From 1947 until into the mid-196os the station kept logs that not only documented the programs in the sequence they were broadcast, but also included complete manuscripts (often with last-minute handwritten edits) for most of the programs and complete listings of records played, as well as usually handwritten notes on the extent to which the broadcast actually went according to plan. 
(Sleutjes 2015a) The detailed nature of the logbooks would allow us to reconstruct programming flow on RNW better than many of the preserved sound records, which are preserved as discreet segments. ${ }^{4}$ Because of their obvious relation to programming, these logbooks also fit well within NISV's existing collection policy, and were among the first items from the RNW collection to be taken on. While most other paper records have remained in storage, the logbooks have been catalogued and available for researchers to consult at NISV since 2015 .

With the logbooks, however, a division of institutional practice has also become a division of archival location. RNW programs were divided according to three different target audiences, defined geographically in terms of the signal's direction and the language of the broadcasts: the Dutch-language service, the International Service (English and Spanish) and the Eastern Service which included broadcasts in Arabic and Indonesian. (Sleutjes 2015b) While the Dutch and International services have come to NISV, the Eastern Service logbooks have found another home in the collection of the Royal Netherlands Institute of Southeast Asian and Caribbean Studies (Koninklijk Instituut voor Taal-, Land-en Volkenkunde, hereafter KITLV) in Leiden, the collections of which have been in the care of the Leiden University library since 2014. The KITLV was founded in 1851 as a research institute dedicated to the linguistic and ethnographic research in the then-Dutch colonies. (see "Our History" n.d.) They have since digitized a selection of the logbooks into pdf documents, one per month of transmission, and placed them online (http://lampje.leidenuniv.nl/KITLV-docs/open/RNW/ rnw.html). Underlying the placement of the "Eastern Service" logbooks at the KITLV was in part the lack of Indonesian or Arabic speakers at NISV. (Sleutjes 2015b) At the same time, however, this separation also makes an interpretation, and even narrative, by moving those programs from 'national heritage' into an institute dedicated to the study of former colonies - a 'them' rather than an 'us.' Services aimed at the other former colonies in the West Indies, however, are included in the material at NISV, rather than the KITLV.

Most of the remaining written archives of the RNW are, as of this writing, in a storage space. While it is impossible to judge precisely what these boxes contain, an inventory of the contents grants a vital overview as to what is there to be selected from and what kinds of stories might be told from the archive. ${ }^{5}$ These include the books of press clippings surrounding various themes, from RNW itself to specific people such as the polyglot presenter of the flagship program Happy Station Edward Startz, and other important personalities. Much of the remaining documentation attests to the role of the international station

4 | See, for example, the Eastern Service for January 1950 (about 77 hours of broadcasting in total), which runs to 1244 pages http://lampje.leidenuniv.nl/KITLV-docs/open/RNW/1950-01.pdf

$\mathbf{5}$ | This section is based upon an Excel sheet inventory the material held in storage. 
not only as a broadcasting organization, but a listening organization, gathering information both from and about listeners, and also other media organizations throughout the world. The station's research department contains various audience measurements over a 20 -year period, and individual departments, in particular Spanish and to a lesser extent Arabic, contain assembled listener correspondence as well. Particularly in many of these relations, RNW's archive can reveal transnational actors and connections. (Hilmes 2017a: 143) The issue of language competence that arose in considering the location of the logbooks will arise once more very clearly in the decision surrounding the various collections of the non-Dutch language desks which make up more or less one third of the material.

In contrast to paper records, preservation of audiovisual contents is largely driven by the considerations of re-use in production. To this end, RNW had a vast digital archive of sound material, searchable and sorted by decade. ${ }^{6}$ Even transfers of digital material are not necessarily straightforward, however: decoding the formatting of the digital archive proved a challenge for NISV. Furthermore, the metadata of a production archive and that of the audiovisual collection at NISV are quite different so that they will need additional enrichment before they can be included in the main catalog. While Dutch-language audiovisual material was brought into the collection without any question, (Lauwers 2017a: 1) as with the logbooks, it is not entirely clear to what extent the foreign language audio material will be selected for keeping as part of the collection, and thus how much of it will be available. In the absence of a clearly-defined policy on language as selection criterion, the selections that do take place will end up as a de facto story of the archive, either rendering a mono- or multilingual version of this chapter of Dutch broadcasting history.

\section{Diffusion Beyond the Collection}

As noted above, in the case of RNW, national archives were considered first and foremost, but the deliberations between NISV and NA did not cover all of the various collected materials from RNW. Some of RNW's collections had already entered into the heavily networked national archive landscape before the cuts took place. Much of the written documentation for Radio Oranje, for example, which had been in the possession of its successor RNW (some of which had initially been in possession of the BBC) was given to the Netherlands Institute for War Documentation (Nederlands Instituut voor Oorlogsdocumentatie, NIOD) in 2009, while its audiovisual collection is at NISV. As such, the movement of

6 | I am grateful to Martien Sleutjes for allowing me to explore this archive before it was transferred. 
RNW's collection will allow the continuities between the organizations to be traced, and the periodization of war and post-war to be explored more closely.

After the 2012 budget cuts, a very different fate befell RNW's music collection of over 20.000 LPs and $50.000 \mathrm{CDs}$, which had been collected and curated separately from the sound and paper archives. About one-third of this collection was 'World Music' acquired by RNW on location in many parts of the world (van Hamersveld 2013), seemingly an extension of the ethnographic concerns of early sound archives to collect the sounds of the world (see Birdsall, this volume). Like the paper archives, these were threatened with destruction if a salvage operation had not been undertaken. The ultimate solution for this material has not been directly a cultural heritage institution but Musidesk, a music lending library in the East of the Netherlands that makes both recordings and sheet music available to a broad public (https://www.musidesk.nl/). While this solution will both preserve the collection and make it accessible, it is not yet clear to what extent this material will be identifiable as originating from RNW and graspable as a collection.

Another moment of diffusion has happened prior, and in parallel, to the formal processes of dealing with RNW's archive. Jonathan Marks, a former director of programs at the station, as well as veteran of both the BBC World Service and freelancer for Radio Austria International, and long-time producer and presenter of RNW's flagship program Media Network, (1981-2000) has worked in parallel to institutional processes to make his personal collection and some of his recollections available online, explicitly for use by scholars and interested amateurs. The program itself documented technical and institutional developments - often in real time - as well as history, across a broad spectrum of the media landscape. It was also pioneering in its use of phone-ins, and was very well-known in the shortwave world (Berg 2010: 243-44). The online Media Network Vintage Vault now has over 485 episodes of the program, including a new 2018 edition, downloadable as podcasts on http://jonathanmarks.libsyn. com/. Each program is given by broadcast date, and accompanied by a short note about the events in it, though without the extensive metadata or categorized metadata that would make it easily linkable in the digital sphere. This collection highlights the increasing amount of valuable historical content that is coming available online in the form of amateur archives, not to mention platforms such as YouTube. (VanCour 2015; Yurtaeva 2016) It is precisely aspects of radio that fall outside of standard national canons of broadcasting, often with transborder reception, which in Europe tend to include 'pirate' and offshore broadcasters, broadcasters such as American Forces Network but also shortwave and DXing communities, that are most often recorded in such informal archives. As both producer of the programs he curates and globally recognized expert on the subject matter they cover (see Berg 2012: 430-32), Marks hardly fits into the category of 'amateur' in terms of his relation to the radio material, 
but rather in his role as archivist and curator. His is a voice that would ideally be brought back into dialogue with formal archives.

\section{CONCLUSION}

Many stories of RNW remain to be told, and thanks to the efforts of the individuals and institutions highlighted here, the sources to support those stories will be preserved and made accessible to scholars and to the broader public within the foreseeable future. Furthermore, as these materials emerge into the digital realm, they have strong potential to be re-collected and interwoven - as radio itself is - into a number of vital stories of transnational heritage: of (post-) colonial migration and diaspora, of the role of a small Western European nation between the Cold War and increasing integration of Europe, of shared experiences and events. At the same time, mapping how traces of international broadcasting find their way within a national archival landscape also holds up a mirror to how archivalization might shape those stories. We have seen here that in many instances a logic of thinking in terms of individual classes of documents rather than a collection as a whole has led to a diffusion of the archive across several institutions. Their re-collection will depend to an increasing extent on their digital tags and metadata, the digital infrastructures in which they move and the finding tools employed to discover them.

In addition, following the paths of RNW's diffusion throws new light on

the question of what constitutes 'the radio archive' in the current era, and in particular what counts as the 'national radio archive'. While VanCour (2016) highlights an ever-widening range of institutions in which diverse radio collections might already be found, this chapter has shown how a single collection might be distributed across a range of institutions, from recognized archival institutions to amateur archives and non-archival organizations. Such diffusion is not only thematically linked to collecting remits, but also highlights the role played by the material to be archived in determining how - and whether - it will become part of a radio archive. While the sound files of programs belong almost without question to the collection, many of the paper records produced by a broadcasting institution would require much deeper scrutiny to be considered worthy of keeping. Indeed the role of paper seems to be moving from one of auxiliary importance to the 'content' of sound files, to one that has importance in its own right (Dolan 2003; Keeler 2011). One of the more intriguing questions regards the various ways in which an international broadcaster listened to, recorded, and understood - and preserved - a view of the world and the radio audience. Beyond that, records such as those of RNTC further open up our view of radio beyond direct production and distribution of programs and 
into a deeper understanding of the transnational production and circulation of radio expertise.

This chapter has above all shown how seemingly 'practical' decisions on archiving can have ideological effects, especially with regard to what constitutes a 'national' radio archive. In a recent lecture, Michele Hilmes has suggested that transnational archives are among those most prone to disappear from history (Hilmes 2017b). The pragmatics of language expertise that separated the Eastern logbooks into a separate institution has both the potential to network and enrich this material around some stories, while at the same time removing them from the 'national' story. To an extent, they even inadvertently mirror the Dutch government's statistical mapping of the population into 'Western' and 'non-Western' foreigners. (cf. Yanow/Haar/Völke 2016) Similar views of a largely monolingual, Western-oriented nation could have similar preservation effects with regard to sound files. Ironically, the preserved and digitized (paper) logbooks might serve as a record of the extent to which those voices have been silenced in the sound archive.

\section{ACKNOWLEDGEMENTS}

Many thanks are due to Martien Sleutjes, Charles Jeurgens, Mieke Lauwers and Bas Agterberg for keeping me abreast of developments with the RNW archive.

\section{REFERENCES}

Badenoch, Alexander, and Berber Hagedoorn (2018): "TV on the Radio/Radio on Television: European Television Heritage as a Source for Understanding Radio History," In: VIEW Journal of European Television History and Culture 7/13, pp. 1-18. https://doi.org/DOI: 10.18146/2213-0969.2018.jethc145.

Berg, Jerome S. (2010): Listening on the Short Waves, 1945 to Today, Jefferson, NC: McFarland.

Berg, Jerome S. (2012): Broadcasting on the Short Waves, 1945 to Today, Jefferson, NC: McFarland.

Briggs, Asa (1970): The War of Words,Oxford: Oxford University Press.

Browne, Donald R. (1982.): International Radio Broadcasting: The Limits of the Limitless Medium, New York: Praeger.

Codding, George Arthur. (1959): Broadcasting Without Barriers, Paris: Unesco.

Dohmen, Joep (2012): “Tot zover de Wereldomroep,” NRC, 21 April 2012. https://www. nrc.nl/nieuws/2012/04/21/tot-zover-de-wereldomroep-1098201-a433765.

Dolan, Josephine (2003): “The Voice That Cannot Be Heard," Radio Journal: International Studies in Broadcast \& Audio Media 1/1, pp. 63-72. 
Gillespie, Marie, and Alban Webb (2013): “Corporate Cosmopolitanism: Diasporas and Diplomacy at the BBC World Service 1932-2012," In: Marie Gillespie/Alban Webb (eds.) Diasporas and Diplomacy: Cultural Contact Zones at the BBC World Service 1932-2012, London: Routledge, pp. 1-20.

Hamersveld, Ineke van. (2013): "Muzikaal Erfgoed Op Straat! Verslag Expertmeeting," Boekman Stichting. 15 April 2013. https://www.boekman.nl/blog/muzikaalerfgoed-op-straat-verslag-expertmeeting.

Haslach, Robert D. (1983): Netherlands World Broacasting, Media, PA: L. Miller.

Hilmes, Michele (2017a): “Entangled Media Histories: A Response,” Media History 23/1, pp. 142-44.

Hilmes, Michele (2017b): "Spies, Commies, and Hairdressers. The Perfidious Entanglements of Media History” Keynote lecture, “Tracing Entanglements in Media History” Lund University May 18

Keeler, Amanda (2011): “'Only the Sound Itself”?: Early Radio, Education, and Archives of 'No-Sound," Sounding Out! (blog), 24 October. https://soundstudiesblog. com/2011/10/24/the-sound-itself-early-radio-education-and-archives-of-no-sound/.

Ketelaar, Eric (2001): “Tacit Narratives: The Meanings of Archives," Archival Science 1/2, pp. 131-41.

Komska, Yuliya (2015): “Sight Radio: Radio Free Europe on Screen, 1951-1965," In: Anna Bischof/Zuzanna Jurgens (eds.) Voices of Freedom - Western Interference? 6o Years of Radio Free Europe in Munich and Prague, Göttingen: Vandenhoeck \& Ruprecht, pp. 55-75.

Lauwers, Mieke (2013) “Collectiebeleid Beeld en Geluid” Policy document, Hilversum: Netherlands Institute for Sound and Vision http://files.beeldengeluid.nl/pdf/Collectiebeleid_BeeldenGeluid.pdf

Lauwers, Mieke (2017a): “Rapportage verloop en uitkomsten Comité des Sages” Internal report, January 2017, Hilversum: Netherlands Institute for Sound and Vision

Lauwers, Mieke (2017b): "Selectiebeleid geschreven archieven Beeld en Geluid. Version 2.0" Internal policy document, October 2017 Hilversum: Netherlands Institute for Sound and Vision

Nelson, Michael (2003): War of the Black Heavens: The Battles of Western Broadcasting in the Cold War, London: Brassey's.

"Our History" (n.d.): KITLV http://www.kitlv.nl/our-history/.

Potter, Simon (2012): Broadcasting Empire: The BBC and the British World, 19221970, Oxford: Oxford University Press.

RNW (1960): Radio Nederland Wereldomroep Jaarverslag 1960, Hilversum: Radio Nederland Wereldomroep

RNW (2012): "Wereldomroep neemt afscheid van de Nederlandse radioluisteraar" Press Release, Radio Nederland Wereldomroep, 25 March 2012 https://web.archive.org/web/20120325204300/http://corporate.rnw.nl/nederlands/persbericht/ wereldomroep-neemt-afscheid-van-de-nederlandse-radioluisteraar 
Robertson, Emma. 2008. “'I Get a Real Kick out of Big Ben' BBC Versions of Britishness on the Empire and General Overseas Service, 1932-1948” Historical Journal of Film, Radio and Television 28/4, pp. 459-73.

Schaap, Wijbrandt (2015): “Archief Wereldomroep volgend slachtoffer van bezuinigingen" https://www.cultureelpersbureau.nl/2015/o1/archief-wereldomroep-volgendslachtoffer-van-bezuinigingen/ 26 January.

Sinke, Onno (2009): Verzet vanuit de verte: de behoedzame koers van Radio Oranje. Augustus.

Sleutjes, Martien (2015a): “Logboeken,"Histomotiv (blog). 24 November. http://www. histomotiv.nl/logboeken/.

Sleutjes, Martien (2015b): 'Logboeken Indonesisch en Arabisch'. Histomotiv (blog). 24 November. http://www.histomotiv.nl/logboeken-indonesisch/.

Spohrer, Jennifer (2013): “Threat or Beacon? Recasting International Broadcasting In Europe After World War II,” In: Alexander Badenoch/Andreas Fickers/Christian Henrich-Franke (eds.) Airy Curtains in the European Ether: Broadcasting and the Cold War. Baden-Baden: Nomos, pp. 29-50.

VanCour, Shawn (2015): “The Informal Economy of the Amateur Archive: Collectors as Cultural Intermediaries,” Flow, May 19. http://www.flowjournal.org/2015/05/ the-informal-economy-of-the-amateur-archive/.

VanCour, Shawn (2016): "Locating the Radio Archive: New Histories, New Challenges," Journal of Radio \& Audio Media 23/2, pp. 395-403.

Wood, James (1994): History of International Broadcasting, London: IET.

Yanow, Dvora/Marleen van der Haar/Karlijn Völke (2016): “Troubled Taxonomies and the Calculating State: Everyday Categorizing and 'Race-Ethnicity' - The Netherlands Case." Journal of Race, Ethnicity and Politics 1/2, pp. 187-226.

Yurtaeva, Yulia (2016): "Private Internetplattformen Als Medienarchive Und Neue Forschungsräume," In: Sascha Trültzsch-Wijnen/Alessandro Barberi/Thomas Ballhausen (eds.), Medienarchive als Gedächtnis- und Erinnerungsorte, Köln: Herbert von Halem, pp. 204-12. 